\title{
Effect of Nalbuphine as Adjuvant to Bupivacaine for Ultrasound-Guided Supraclavicular Brachial Plexus Block
}

\author{
Mohamed Mohamed Abdelhaq ${ }^{1 *}$, Mohamed Adly Elramely ${ }^{2}$ \\ ${ }^{1}$ Faculty of Medicine, Cairo University, Giza, Egypt \\ ${ }^{2}$ National Cancer Institute, Cairo University, Giza, Egypt \\ Email: *mohamedabdelhaq76@hotmail.com, mramely@hotmail.com
}

Received 6 February 2016; accepted 14 March 2016; published 17 March 2016

Copyright (C) 2016 by authors and Scientific Research Publishing Inc.

This work is licensed under the Creative Commons Attribution International License (CC BY). http://creativecommons.org/licenses/by/4.0/

\section{(c) (i) Open Access}

\section{Abstract}

Background: Nalbuphine is a derivative of 14-hydroxymorphine which is a strong analgesic with mixed $k$ agonist and $\mu$ antagonist. Nalbuphine was studied several times as adjuvant to local anesthetics in spinal, epidural and local intravenous block. The aim of this study was to evaluate the effect of nalbuphine as an adjuvant to local anesthetics in supraclavicular brachial plexus block. Patients and Methods: Fifty-six patients undergoing elective forearm and hand surgery under supraclavicular brachial plexus block were allocated randomly into one of two groups of 28 patients each to receive either 25 $\mathrm{ml}(0.5 \%)$ bupivacaine with $1 \mathrm{ml}$ of $\mathrm{NS}$ or $25 \mathrm{ml}(0.5 \%)$ bupivacaine with $1 \mathrm{ml}(20 \mathrm{mg})$ nalbuphine. Onset time and duration of both sensory and motor block, and post-operative analgesia were observed. Result: Nalbuphine group showed significant increase in the duration of motor block (412.59 \pm 18.63), when compared to control group (353.70 \pm 29.019) $p$-value $<0.001$, also, there was significant increase in sensory duration in nalbuphine group $(718.14 \pm 21.04)$ when compared to control group $(610.18 \pm 26.33)$ p-value $<$ 0.001 , without affecting the onset time of the blockade. And also, there was a significant increase in the duration of analgesic effect in nalbuphine group $(835.18 \pm 42.45)$ when compared to control group (708.14 $\pm \mathbf{5 4 . 5 7 )}$ p-value $<\mathbf{0 . 0 0 1}$. Conclusion: The present study demonstrates that addition of $20 \mathrm{mg}$ nalbuphine to bupivacaine in supraclavicular brachial plexus block is associated with significant increase in the duration of both sensory and motor block and also prolong the duration of analgesia.

"Corresponding author.

How to cite this paper: Abdelhaq, M.M. and Elramely, M.A. (2016) Effect of Nalbuphine as Adjuvant to Bupivacaine for UItrasound-Guided Supraclavicular Brachial Plexus Block. Open Journal of Anesthesiology, 6, 20-26. 


\section{Keywords}

Supraclavicular Block, Local Anesthetic, Ultrasound, Nalbuphine

\section{Background}

Brachial plexus block is a versatile and reliable regional anesthetic technique with multiple applications. Nowadays, it is a suitable alternative to general anesthesia for certain patients. Brachial plexus block is most commonly used regional nerve block of the upper extremity, which avoids the undesired effect of anesthetic drugs used during general anesthesia and the stress of laryngoscopy and tracheal intubation. Patients can also enjoy postoperative period free from nausea, vomiting, cerebral depression and immediate postoperative pain [1].

The supraclavicular brachial plexus block has many advantages over other approaches to brachial plexus block. It provides complete and reliable anesthesia for upper limb surgery. It is performed at the level of the trunk where the plexus is presented most compactly [2].

It is always the interest of an anesthetist to increase the quality of local anesthetics, by increasing the duration of the block and decrease the incidence of local anesthetic toxicity. So many adjuvants added to local anesthetics to prolong the block duration and reduce the toxicity, like opioids [3], dexamethasone [4], and clonidine [5].

Nalbuphine was studied several times as an adjuvant to local anesthetics in spinal, epidural and local, intravenous block, and the result of all studies concludes that nalbuphine is effective when used as an adjuvant to local anesthetics in spinal, epidural, and local intravenous block, as it significantly prolongs the block duration.

Nalbuphine is a derivative of 14-hydroxymorphine which is a strong analgesic with mixed $\mathrm{k}$ agonist and $\mu$ antagonist. The analgesic effect of nalbuphine has been found to be equal to the analgesic effect of morphine but unlike it has a ceiling effect on respiration. Nalbuphine has the potential to maintain or even enhance $\mu$-opioid based analgesic effect while simultaneously mitigating the $\mu$-opioid side effects [6].

\section{Objective of Study}

Nalbuphine was studied several times as adjuvant to local anesthetics in spinal, epidural and local intravenous block. The aim of this study was to evaluate the effect of nalbuphine as an adjuvant to local anesthetics in peripheral nerve block, so we compare the effect of a combination of nalbuphine and bupivacaine versus bupivacaine alone in supraclavicular brachial plexus block for the patients undergoing elective upper limb surgeries.

\section{Patients and Methods}

This double-blinded randomized controlled clinical trial was carried out in Kasr Al-Ainy hospital, faculty of medicine, Cairo University, between June 2014 and October 2015. After obtaining approval of the departmental scientific and ethical committee, fifty-six ASA physical status I and II patients of sexes, 18 - 60 years old, undergoing elective forearm and hand surgery in orthopedic and plastic surgical operating theater were included in the study. The exclusion criteria of this study were; patient refusal for the procedure, any bleeding tendency or patient on oral anticoagulants, neurological deficits involving brachial plexus, patients with allergy to local anesthetics, local infection at the site of injection, patients on any sedatives or antipsychotics, and body mass index $>35$.

Patients were randomly allocated into two equal study groups. The randomization sequence was concealed in opaque sealed envelopes that were kept by the senior anesthesia staff. The envelope was opened at the beginning of the operation before initiation of the block after obtaining written informed consent from the patients. Patients will be distributed into two groups.

Group-C: control group, 28 patients will receive $25 \mathrm{ml}$ of $\mathrm{ml}$ of bupivacaine $0.5 \%$ and $1 \mathrm{ml}$ normal saline.

Group-N: nalbuphine group, 28 patients will receive $25 \mathrm{ml}$ of $\mathrm{ml}$ of bupivacaine $0.5 \%$ and nalbuphine $1 \mathrm{ml}$ (20 mg).

\subsection{Primary Outcomes}

1) The onset of sensory and motor blockade.

2) Duration of sensory and motor blockade. 
3) Duration of analgesia (first request for analgesic).

\subsection{Secondary Outcome Parameters}

1) Blood pressure (BP).

2) Respiratory rate.

3) Oxygen saturation $\left(\mathrm{SpO}_{2}\right)$.

All patients were subject to systematic preoperative assessment including history taking, physical examination, and review of the results of routine investigations. Visual analogue pain score (VAS) was explained to all candidates where zero corresponds to no pain and 10 is indicative of the worst unbearable pain.

On arrival to the preparation room: A 20 gauge IV cannula was inserted into a peripheral vein in the contralateral arm. Patients were sedated by $0.01-0.05 \mathrm{mg} / \mathrm{kg}$ of intravenous midazolam, additional intravenous fentanyl $1 \mathrm{mic} / \mathrm{kg}$ was added as needed (to keep moderate sedation; arousable on command). Patients were then transferred to the operating room where basic monitoring (Electrocardiography (ECG), Non-invasive Blood Pressure (NIBP) and pulse oximetry $\left(\mathrm{SpO}_{2}\right)$ ) were attached. Baseline heart rate, blood pressure, oxygen saturation and respiratory rate were recorded as pre-block values.

The patient was placed in supine position with the head turned 45 degrees to the contralateral side. An ultrasound machine (Mindray M7) and a $12 \mathrm{MHz}$ linear type probe were used. After skin preparation and local anesthetic infiltration of skin, the supraclavicular fossa was scanned to locate the subclavian artery, first rib, pleura and brachial plexus cluster, and then a 22 gauge, $5 \mathrm{~cm}$, echogenic needle (B. Braun) was advanced from the lateral to medial in the long axis of the ultrasound beam. The needle was advanced towards the 'corner pocket', where the lower trunk commonly lies in this area (between the subclavian artery medially, the first rib inferiorly and the plexus superiorly), and then half volume of prepared local anesthetic mixture either with $1 \mathrm{ml}$ saline or with $20 \mathrm{mg}$ nalbuphine was injected, then we repositioned the needle cranially toward the neural cluster in order to apply the remaining volume of local anesthetic just above and lateral to subclavian artery.

During the intraoperative period; heart rate, blood pressures will be noted every 5 minutes (min) during the first $15 \mathrm{~min}$., and then every $15 \mathrm{~min}$. throughout the surgery. Inadequate sensory and motor blockade beyond 30 min following the infiltration of local anaesthetics will be considered as an unsuccessful block.

After the procedure, patients were taken for surgery, and we observed the onset of both sensory and motor blockade, duration of both motor and sensory blockade and duration of analgesia (first request for an analgesic) was measured by interviewing the patient in the early postoperative period (2 hours). Patients were monitored routinely, and any side effects were noted. In the postoperative period if patients started to complain (VAS > 3); rescue analgesia was given in the form of pethidine $1 \mathrm{mg} / \mathrm{kg}$, paracetamol (Perfalgan ${ }^{\circledR}$ ) 1 gm IV drip and/or diclofenac sodium $\left(\right.$ Voltaren $^{\circledR}$ ) $75 \mathrm{mg}$ IM, till VAS $\leq 3$.

\subsection{Statistical Analysis}

Assuming that the mean duration of the sensory block of bupivacaine is 4 hours, two-tailed $\alpha$ error probability of 0.05 and $\beta$ error probability of 0.2 (power of $80 \%$ ); a total sample size of 56 patients randomly allocated into two equal groups (28 patients per group) will be required to detect a presumed minimum clinically significant increase of $10 \%$ in the duration of sensory block.

All the statistical analyzes were performed using The SPSS software (version 14.0; SPSS Inc, Chicago, IL, USA). Data presented as a mean and standard deviation or number and percentage. The t-test was used to examine the differences between means. Statistical significance was accepted for a P-value of $<0.05$.

\section{Results}

A total of 66 patients were assessed for eligibility to our study, but six patients not meeting inclusion criteria and other four patients were declined to participate so ten patients were excluded from the study. Fifty-six ASA physical status I and II patients of both sex, 18 - 60 years old, undergoing forearm surgery and hand surgery in orthopedic, and plastic surgical operating theater of Kasr Al-Ainy hospital who fulfilled the inclusion criteria, had been enrolled in the study. All enrolled patients have already completed the study. Those patients were randomly allocated into two groups, 28 patients each.

Demographic data including (age, gender, weight, ASA classification and duration of surgery) did not show 
any statistically significant difference between the two studied groups. About 75\% of the total study population was ASA class I, Table 1.

Regarding sensory and motor block onset, results showed that nalbuphine group had a rapid onset of both motor and sensory but without a statistically significant difference, p-value $>0.05$ as demonstrated in Table 2 .

The results were found as regards the motor block duration; the motor block duration was longer in Nalbuphine group when compared to control group, and these differences were statistically significant, p-value < 0.001 , Table 3.

Nalbuphine group showed delayed sensory block regression, with statistically significant differences when compared to control group (p-value $<0.001$ ).

When comparing the duration of analgesia following nerve block administration, a significant difference was found between Nalbuphine group and control group (p-value $<0.001$ ), Table 4.

The nerve blockade administered was successful in all patients of the studied groups. None of the patients required rescue analgesia intraoperatively or postoperatively in the Post-Anesthesia Care Unit (PACU). No block related change in hemodynamics and no block related toxicity of local anesthetics.

Table 1. Demographic data.

\begin{tabular}{ccc}
\hline & Nalbuphin group $(\mathrm{n}=28)$ & Control group $(\mathrm{n}=28)$ \\
\hline Age (years) & $44 \pm 6.5$ & $48 \pm 5.4$ \\
Sex & & $18(64 \%)$ \\
1 Male & $16(57 \%)$ & $10(36 \%)$ \\
Female & $12(43 \%)$ & $22(78.5 \%)$ \\
ASA $^{\dagger}$ classification & & $6(21.5 \%)$ \\
I & $20(71.5 \%)$ & $68 \pm 0.96$ \\
II & $8(28.5 \%)$ & $2.5 \pm 1.13$ \\
\hline
\end{tabular}

Data are described as mean \pm SD or number of patients (percentage $\%$ ); ${ }^{\dagger}$ ASA: American Society of Anesthesiologists.

Table 2. Onset of sensory and motor blockade.

\begin{tabular}{cccc}
\hline & Group N (n= 28) & Group C (n= 28) & p-value \\
\hline Onset of sensory block (min.) & $8.64 \pm 0.717$ & $9.18 \pm 1.37$ & 0.083 \\
Onset of motor block (min.) & $17.4 \pm 1.14$ & $18 \pm 1.50$ & 0.116 \\
\hline
\end{tabular}

${ }^{*}$ p value $<0.05$ is considered statistically significant

Table 3. Duration of sensory and motor blockade.

\begin{tabular}{lccc}
\hline & Group N (n=28) & Group C (n=28) & p-value \\
\hline Duration of sensory block (min.) & $718.14 \pm 21.04$ & $610.18 \pm 26.33$ & $<0.001$ \\
Duration of motor block (min.) & $412.59 \pm 18.63$ & $353.70 \pm 29.019$ & $<0.001$ \\
\hline
\end{tabular}

${ }^{*}$ p value $<0.05$ is considered statistically significant.

Table 4. Analgesia duration.

\begin{tabular}{lccc} 
& Group N $(\mathrm{n}=28)$ & Group C $(\mathrm{n}=28)$ & p-value \\
\hline Duration of analgesia (min.) & $835.18 \pm 42.45$ & $708.14 \pm 54.57$ & $<0.001$
\end{tabular}

${ }^{*}$ p value $<0.05$ is considered statistically significant. 


\section{Discussion}

The result of our study showed that addition of $20 \mathrm{mg}$ nalbuphine to $0.5 \%$ bupivacaine for supraclavicular brachial plexus block results in significant increase in the duration of motor block (412.59 \pm 18.63$)$, when compared to control group (353.70 \pm 29.019$)$, also, there was significant increase in sensory duration in nalbuphine group (718.14 \pm 21.04 ) when compared to control group (610.18 \pm 26.33 ), without affecting the onset time of the blockade. And also, there was a significant increase in the duration of analgesic effect in nalbuphine group (835.18 \pm 42.45$)$ when compared to control group (708.14 \pm 54.57$)$.

Nalbuphine was studied as an adjuvant to local anesthetics in epidural, caudal, and intrathecal anesthesia [7] [8]. But after research in the literature, we did not find any published data studying the effect of nalbuphine when used as an adjuvant to local anesthetics in peripheral nerve block.

Nalbuphine is a mixed k-agonist- $\mu$-antagonist opioid with a moderate analgesic effect when compared to morphine. Its affinity to k-opioid receptors results in analgesia, sedation, and cardiovascular stability with minimal respiratory depression. There is a great similarity between butorphanol and nalbuphine regarding the chemical nature (synthetic mixed k-agonist- $\mu$-antagonists), also, both have the same mode of action on opioid receptors, and inhibition of neuronal serotonin uptake which leads to augmentation of the spinal inhibitory pathways for pain [9]. Stimulation of opiate receptors on neurons of the central nervous system lead to an inhibition of intracellular adenylyl cyclase, an opening of potassium channels, and closing the calcium channels. This leads to hyperpolarization of the cell membrane potential and inhibition of action potential transmission of ascending pain pathways [10].

For many years ago, different types of opioids (fentanyl, morphine, tramadol, and butorphanol) have been added to local anesthetics in peripheral nerve block to improve the quality and increase the duration of anesthesia and post-operative analgesia. Ranjit et al, studied the effect of 2 mg butorphanol as adjuvant to bupivacaine in supraclavicular nerve block to the patients scheduled for elective surgery of hand and forearm, and concluded that butorphanol prolongs the duration of supraclavicular brachial plexus block when given along with bupivacaine. And they explained the effect of butorphanol through stimulation of opioid receptor on neurons of the central nervous system [10]. Kapral et al. added tramadol to mepivacaine in axillary brachial plexus block and found that the mixture of $100 \mathrm{mg}$ tramadol and 1\% mepivacaine provides a significant prolongation of the axillary plexus blockade without side effects. And they explained the effect of tramadol through affecting the opiate receptors by tramadol and its metabolites [11]. Wajima et al. showed that continuous infusion of butorphanol locally into the brachial plexus sheath provided a better analgesic effect to that of continuous intravenous systemic injection [12]. In another study, Wajima et al. found that butorphanol $2 \mathrm{mg}$ with 0.5\% mepivacaine provides sufficient postoperative analgesia after upper limb surgery [13]. So these previous studies demonstrated that different types of opioids act well on peripheral nerve through stimulation of opioid receptor.

The result of our study correlates well with VeenaChatrath, et al. who compared the postoperative analgesic effect of both tramadol and nalbuphine when used epidurally in patients undergoing lower limb orthopedic surgery. And concluded that nalbuphine group was better regarding a better quality of surgical analgesia, lesser incidence of side-effects and complications [14]. Yoon et al. studied 60 female patients scheduled for the caesarean section under spinal anesthesia to receive $0.1 \mathrm{mg}$ morphine or $1 \mathrm{mg}$ nalbuphine or $0.1 \mathrm{mg}$ morphine with 1 mg nalbuphine in addition to $10 \mathrm{mg}$ 0.5\% bupivacaine and concluded that effective analgesia was prolonged in the morphine group and morphine with nalbuphine group [15]. Hala et al who compared the effect of intrathecally nalbuphine to fentanyl in Sixty female patients undergoes elective cesarean deliveries with spinal anesthesia, and concluded that either intrathecal nalbuphine $(0.8 \mathrm{mg})$ combined with $(10 \mathrm{mg})$ bupivacaine or intrathecal fentanyl $(25 \mu \mathrm{g})$ combined with $(10 \mathrm{mg})$ bupivacaine prolong early post-operative analgesia without any statistically significant difference between both groups [16]. Shehla Shakooh et al, who used nalbuphine (preservative free) $0.8 \mathrm{mg}$ as an adjuvant to intrathecal hyperbaric bupivacaine (0.5\%) for various lower abdominal and lower limb surgeries and compared its postoperative analgesic effect under spinal anaesthesia to hyperbaric bupivacaine (0.5\%) alone, and they concluded that, nalbuphine as an adjuvant to spinal anaesthesia shortens the onset of sensory and motor block, prolongs duration of sensory and motor blockade, provides effective postoperative analgesia, provides desirable sedation intraoperatively and does not result in any major adverse effects [17]. Culebras et al. compared the different doses of nalbuphine when given intrathecally in doses of $0.2 \mathrm{mg}, 0.8$ $\mathrm{mg}$ and $1.6 \mathrm{mg}$ in 90 obstetric patients undergoing a caesarean section and found that, $0.8 \mathrm{mg}$ as the most effective dosage [18]. Arghya Mukherjee et al, who studied the effect of nalbuphine when used as an adjuvant to $0.5 \%$ 
hyperbaric bupivacaine in spinal anesthesia, and concluded that, $0.4 \mathrm{mg}$ of nalbuphine is the most effective dose that prolongs duration of analgesia early postoperatively without increasing the risk of side-effects. So they recommended that the optimal dose of nalbuphine, when used intracecally along with $12.5 \mathrm{mg} 0.5 \%$ hyperbaric bupivacaine for spinal anesthesia in patients undergoing orthopedic surgeries in lower limb, is $0.4 \mathrm{mg}$ of nalbuphine [19]. Maha M.I et al; which compared the effect of nalbuphine as adjuvants to lidocaine in intravenous regional anesthesia to tramadol effects, and they concluded that both nalbuphine and tramadol effects were comparable. However, nalbuphine was proved to be more effective than tramadol in prolonging the duration of postoperative analgesia [20].

\section{Conclusion}

The present study demonstrates that the addition of $20 \mathrm{mg}$ nalbuphine to bupivacaine in supraclavicular brachial plexus block in patients undergoing forearm and hand surgeries is associated with a significant increase in the duration of both sensory and motor block and also prolongs the duration of postoperative analgesia.

\section{Conflict of Interest}

No conflict of interest.

\section{References}

[1] Neal, J.M., Gerancher, J.C., Hebl, J.R. and Ilfeld, B.M. (2009) Upper Extremity Regional Anaesthesia. Regional Anesthesia and Pain Medicine, 34, 134-170. http://dx.doi.org/10.1097/AAP.0b013e31819624eb

[2] Singh, A., Gupta, R., Vashisth, M., Singh, S., Kumari, A. and Aujla, K.S. (2010) Comparison of Effectiveness of Brachial Plexus Block by Supraclavicular and Axillary Approach Alone or in Combination. Journal of Anaesthesiology Clinical Pharmacology, 26, 31-34.

[3] Saryazdi, H., Yazdani, A., Sajedi, P. and Aghadavoudi, O. (2015) Comparative Evaluation of Adding Different Opiates (Morphine, Meperidine, Buprenorphine, or Fentanyl) to Lidocaine in Duration and Quality of Axillary Brachial Plexus Block. Advanced Biomedical Research, 4, 232-237.

[4] Kim, Y.J., Lee, G.Y., Kim, D.Y., Kim, C.H., Baik, H.-J. and Heo, S. (2012) Dexamathasone Added to Levobupivacaine Improves Postoperative Analgesia in Ultrasound Guided Interscalene Brachial Plexus Blockade for Arthroscopic Shoulder Surgery. Korean Journal of Anesthesiology, 62, 130-134. http://dx.doi.org/10.4097/kjae.2012.62.2.130

[5] Khasar, S.G., Green, P.G., Chou, B. and Levine, J.D. (1995) Peripheral Nociceptive Effects of Alpha 2-Adrenergic Receptor Agonists in the Rat. Neuroscience, 66, 427-432. http://dx.doi.org/10.1016/0306-4522(94)00562-J

[6] Gunion, M.W., Marchionne, A.M. and Anderson, T.M. (2004) Use of the Mixed Agonist-Antagonist Nalbuphine in Opiod Based Analgesia. Acute Pain, 6, 29-39. http://dx.doi.org/10.1016/j.acpain.2004.02.002

[7] Jyothi, B., Gowda, S. and Shaikh, S.I. (2014) A Comparison of Analgesic Effect of Different Doses of Intrathecal Nalbuphine Hydrochloride with Bupivacaine and Bupivacaine Alone for Lower Abdominal and Orthopedic Surgeries. Indian Journal of Pain, 28, 18-23. http://dx.doi.org/10.4103/0970-5333.128881

[8] Yeh, Y.-C., Lin, T.-F., Lin, F.-S., Wang, Y.-P., Lin, C.-J. and Sun, W.-Z. (2008) Combination of Opioid Agonist and Agonist-Antagonist: Patient-Controlled Analgesia Requirement and Adverse Events among Different-Ratio Morphine and Nalbuphine Admixtures for Postoperative Pain. British Journal of Anaesthesia, 101, 542-548. http://dx.doi.org/10.1093/bja/aen213

[9] Gear, R.W., Miaskowski, C. and Gorden, N.C. (1999) The Kappa Opioid Nalbuphine Produces Gender and Dose Dependent Analgesia and Antianalgesia in Patients with Postoperative Pain. Pain, 83, 339-345. http://dx.doi.org/10.1016/S0304-3959(99)00119-0

[10] Acharya, R., Jena, M., Mishra, S. and Rath, S.K. (2014) Effect of Butorphanol versus Placebo as Adjuvant to Bupivacaine for Supraclaviculare Brachial Plexus Blockade. International Journal of Applied Pharmaceutics, 6, 8-10.

[11] Kapral, S., Gollmann, G., Waltl, B., Likar, R., Sladen, R.N., Weinstabl, C. and Lehofer, F. (1999) Tramadol Added to Mepivacaine Prolongs the Duration of an Axillary Brachial Plexus Blockade. Anesthesia \& Analgesia, 88, 853-856.

[12] Wajima, Z., Nakajima, C. and Kim, C. (1995) Compared with Brachial Plexus Infusion of Butorphanol for Postoperative Analgesia. British Journal of Anaesthesia, 74, 392-395. http://dx.doi.org/10.1093/bja/74.4.392

[13] Wajima, Z., Shitara, T. and Nakajima, Y. (1997) Continuous Brachial Plexus Infusion of Butorphanol-Mepivacaine Mixtures for Analgesia after Upper Extremity Surgery. British Journal of Anaesthesia, 78, 83-85.

http://dx.doi.org/10.1093/bja/78.1.83 
[14] Chatrath, V., Attri, J.P., Bala, A., Khetarpal, R., Ahuja, D. and Kaur, S. (2015) Epidural Nalbuphine for Postoperative Analgesia in Orthopedic Surgery. Anesthesia: Essays and Researches, 9, 326-330. http://dx.doi.org/10.4103/0259-1162.158004

[15] Yoon, J.Y., Jee, Y.S. and Hong, J.Y. (2002) A Comparison of Analgesic Effects and Side Effects of Intrathecal Morphine, Nalbuphine and Morphine-Nalbuphine Mixture for Pain Relief during a Caesarean Section. Korean Journal of Anesthesiology, 42, 627-633. http://dx.doi.org/10.4097/kjae.2002.42.5.627

[16] Gomaa, H.M., Mohamed, N.N., Zoheir, H.A.H. and Ali, M.S. (2014) A Comparison between Post-Operative Analgesia after Intrathecal Nalbuphine with Bupivacaine and Intrathecal Fentanyl with Bupivacaine after Cesarean Section. European Journal of Anaesthesiology, 30, 405-410.

[17] Shakooh, S. and Bhosle, P. (2014) Intrathecal Nalbuphine: An Effective Adjuvant for Post Operative Analgesia. Innovative Journal of Medical and Health Science, 4, 79-82.

[18] Culebras, X., Gaggero, G., Zatloukal, J., Kern, C. and Marti, R.A. (2000) Advantages of Intrathecal Nalbuphine, Compared with Intrathecal Morphine, after Cesarean Delivery: An Evaluation of Postoperative Analgesia and Adverse Effects. Anesthesia \& Analgesia, 91, 601-605. http://dx.doi.org/10.1213/00000539-200009000-00019

[19] Mukherjee, A., Pal, A., Agrawal, J., Mehrotra, A. and Dawar, N. (2012) Intrathecal Nalbuphine as an Adjuvant to Subarachnoid Block: What Is the Most Effective Dose. Anesthesia: Essays and Researches, 5, 171-175.

[20] Youssef, M.M.I. and ElZayyat, N.S. (2014) Lidocaine-Nalbuphine versus Lidocaine-Tramadol for Intravenous Regional Anesthesia. Ain-Shams Journal of Anaesthesiology, 7, 198-204. http://dx.doi.org/10.4103/1687-7934.133441 